\title{
Multidisciplinary Design Optimization of Low-Airframe-Noise Transport Aircraft
}

\author{
Leifur T. Leifsson * \\ Airbus UK, Filton, Bristol, BS99 7 AR, Great Britain \\ William H. Mason ${ }^{\dagger}$ and Joseph A. Schetz ${ }^{\ddagger}$ \\ Virginia Tech, Blacksburg, VA \\ Raphael T. Haftka § \\ University of Florida, Gainesville, FL \\ Bernard Grossman \\ National Institute of Aerospace, Hampton, VA
}

The objective of this research is to examine how to design low-airframe-noise transport aircraft using Multidisciplinary Design Optimization (MDO). This involves optimizing aircraft to minimize maximum-take-off-weight, while constraining noise at the approach condition. A design methodology which incorporates noise as a design constraint into an MDO formulation is presented. An MDO framework was designed by integrating aircraft conceptual design tools previously developed at Virginia Tech with the Aircraft Noise Prediction Program (ANOPP). Design studies are presented for cantilever wing and Strut-Braced Wing (SBW) transport aircraft with 300 passengers and a 7,700 $\mathrm{nm}$ range. The results show that reducing airframe noise by reducing approach speed alone, will not provide significant noise reduction without a large performance and weight penalty. Therefore, more dramatic changes to the aircraft design are needed to achieve a significant airframe noise reduction. Another study showed that the trailing-edge (TE) flap can be eliminated, as well as all the noise associated with that device, without incurring a significant weight and performance penalty. If noise due to the leading-edge (LE) slats and landing gear are reduced, which is currently being pursued, the elimination of the flap will be very significant as the clean wing noise will be the next 'noise barrier'. Lastly, an airframe noise analysis showed that a SBW aircraft, with short fuselage-mounted landing gear, could have a similar or potentially a lower airframe noise level than a cantilever wing aircraft.

\section{Nomenclature}

$\begin{array}{ll}C_{L_{\text {app }}} & \text { Approach lift coefficient } \\ & =\frac{W_{\text {land }}}{q S_{\text {ref }}} \\ C_{L_{\max }} & \text { Maximum lift coefficient } \\ & =\frac{M T O G W}{q S_{\text {ref }}} \\ C_{L_{\text {max }} \text { limit }} & \text { Maximum theoretical lift coefficient for a given type of high-lift system }\end{array}$

\footnotetext{
*Wing Integration Engineer, Aerodynamics Department, Building 09B, Member AIAA, leifur.leifsson@airbus.com

$\dagger$ Professor, Department of Aerospace and Ocean Engineering, Associate Fellow AIAA, whmason@vt.edu

${ }^{\ddagger}$ Fred D. Durham Endowed Chair, Professor, Department of Aerospace and Ocean Engineering, Fellow AIAA, ptiger@vt.edu

$\S$ Distinguished Professor,Department of Mechanical and Aerospace Engineering, Fellow AIAA, haftka@ufl.edu

ףVice President, Education, NIA, 1000 Exploration Way, Hampton, VA 23666, Fellow AIAA, grossman@nianet.org
} 


$\begin{array}{ll}\text { MTOGW } & \text { Maximum Take-Off Gross Weight } \\ N_{\text {ref }} & \text { Reference aircraft configuration noise level } \\ N_{\text {new }} & \text { New aircraft configuration noise level } \\ \Delta N & \text { Target noise reduction } \\ S_{f} & \text { TE flap surface area } \\ S_{\text {ref }} & \text { Wing reference area } \\ q & \text { Dynamic pressure } \\ & =1 / 2 \rho V^{2} \\ V & \text { Aircraft speed } \\ W_{\text {land }} & \text { Aircraft landing weight } \\ \rho & \text { Air density } \\ \delta_{f} & \text { TE flap deflection } \\ \alpha & \text { Angle of attack } \\ \alpha_{\text {app }} & \text { Approach angle of attack } \\ \alpha_{\text {stall }} & \text { Stall angle of attack } \\ \alpha_{\text {limit }} & \text { Maximum allowable angle of attack } \\ \theta_{t s} & =\theta_{t s}-\gamma_{g s} \\ \gamma_{g s} & \text { Tail scrape angle } \\ & \text { Glide slope angle }\end{array}$

\section{Introduction}

Aircraft main noise sources are the engines, the airframe, and the interference between the engines and the airframe. During take-off and flyover, when the engines develop maximum power, the engines are the dominant noise source. The noise generated by the airframe is normally significant only during the approach. Airframe noise sources on a conventional transport, shown in Figure 1, are the landing gear, trailing edge (TE) flaps, leading edge (LE) slats, the clean wing, and the tail surfaces. ${ }^{1}$ The LE slats, flap edges, and the landing gear are the major contributors to airframe noise and the main landing gear is the dominant noise source on most modern wide-body transports. ${ }^{2}$

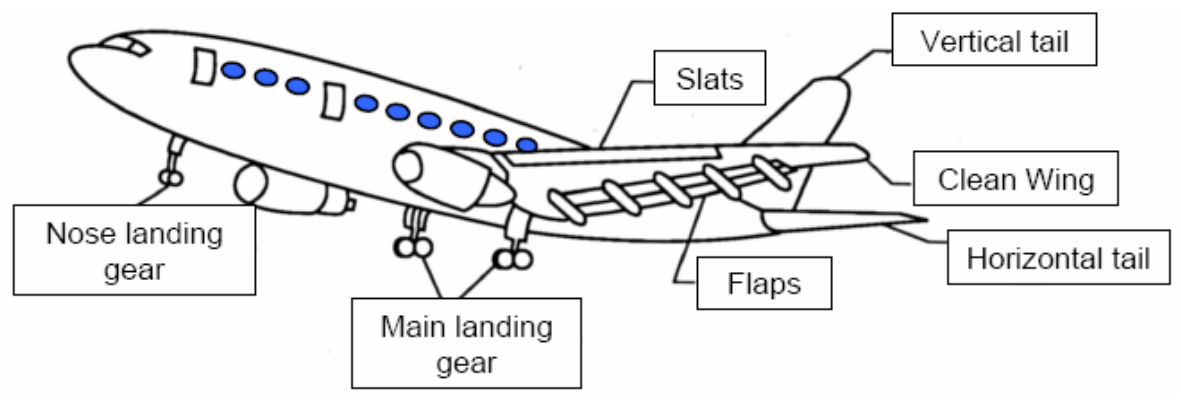

Figure 1. Airframe noise sources (from Hosder ${ }^{3}$ ).

Civil transport aircraft must be certified in terms of noise levels set by the FAA in FAR Part $36^{4}$ and ICAO in Annex $16 .^{5}$ For certification, the noise is measured at three different locations near the runway (Figure 2): (1) flyover, which is $6.5 \mathrm{~km}$ from the brake release point and under the take-off flight path where the aircraft is climbing with reduced power, (2) the highest measurement recorded at the sideline $(450 \mathrm{~m}$ from the runway axis) during take-off with max take-off power rating, and (3) at approach, which is $2 \mathrm{~km}$ from the runway threshold and under the flight path, with the aircraft at $120 \mathrm{~m}$ altitude and with a 3 degree glide slope, and the aircraft is in its noisiest configuration with landing gear extended and full flap deflection.

The Effective Perceived Noise Level (EPNL) is limited by FAA and ICAO regulations based on aircraft maximum take-off weight and the number of engines. In addition to these constraints, regulations limit the operations hours, and the number of operations at most airports. There has been approximately a $100 \%$ increase in the number of noise related restrictions in the last decade, and the number of airports affected by these noise restrictions has grown significantly worldwide. ${ }^{6}$ NASA's goal is to reduce aircraft noise by 10 


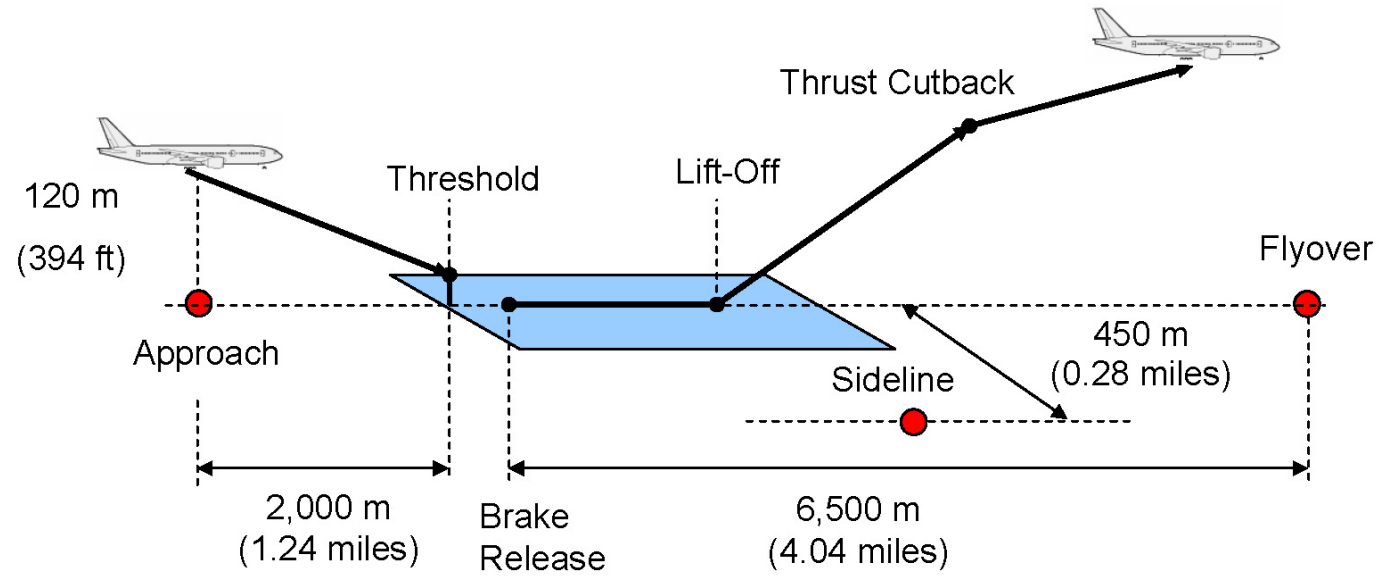

Figure 2. ICAO and FAR noise certification points.

decibels by the year $2007^{7}$ to meet the more stringent noise levels and regulations. This goal is scientifically demanding, because it means reducing the acoustic power by $90 \%{ }^{8}$ NASA's long term goal, within the next 20 years, is to reduce aircraft noise by 20 decibels. It is clear that to achieve these noise reduction goals a significant research effort is required. However, if the aircraft can be designed/modified so that it has some leeway within these constraints, airlines can gain improvement in their operations and relief will be provided to the airport's surrounding community. This provides a strong incentive for reduction in aircraft noise.

Usually, aircraft have been designed to meet performance and weight goals and then adjusted to satisfy the environmental and noise requirements at the later stages in the design process. Due to the coupled nature of the design it is clear that to meet all the required constraints as well as achieving the best possible solution, all the different disciplines and constraints need to be considered simultaneously. Recent research has focused on introducing noise into the earlier stages of aircraft design using Multidisciplinary Design Optimization (MDO). Caves et al. ${ }^{9,10}$ developed a model that integrates a conceptual aircraft design model with the Aircraft Noise Prediction Program (ANOPP). ${ }^{11}$ The model was used to study the effect of changing the thrust/weight ratio on the take-off flyover noise levels and the sensitivity of approach angle to approach noise levels. Results showed that increasing the altitude during the approach phase significantly reduces approach noise.

Antoine et al. ${ }^{6,12-14}$ used MDO to design the aircraft and mission to meet specified noise constraints at flyover, sideline, and approach conditions. Abatement procedures such as steeper approaches and thrust cutback on take-off were also included in the analysis. The results showed that engine bypass ratio was a driving factor in reducing engine noise. Furthermore, steeper approaches can effectively reduce approach noise.

The Blended-Wing-Body (BWB) aircraft has been recognized as the ultimate low-noise aircraft configuration. ${ }^{3,15} \mathrm{NASA}^{16-18}$ has done research on propulsion-airframe-aeroacoustic technologies for a BWB aircraft with an array of small turbofan engines which focused on reducing engine noise. Manneville et al. ${ }^{19}$ studied BWB aircraft with a distributed propulsion system with multiple ultra-high bypass ratio engines and reported a $30 \mathrm{~dB}$ reduction in jet noise could be attainable with such a configuration.

This paper introduces methodology for incorporating noise constraints in the aircraft conceptual design phase using MDO, and focusing on reducing airframe noise. The MDO framework presented here, integrates aircraft conceptual design tools previously developed at Virginia Tech (VT) ${ }^{20-22}$ with ANOPP, and is capable of analyzing and optimizing both cantilever wing and Strut-Braced Wing (SBW) aircraft.

\section{Design Methodology}

Minimal changes are needed to an MDO formulation if the aircraft noise is added as a design constraint. A sensible approach to this problem is to start by optimizing the aircraft for minimum TOGW subject to conventional design constraints without considering noise. This aircraft, that is conventionally designed and optimized, will be the reference configuration. The next step is to analyze the reference configuration 
at the desired flight condition (in our case at approach) to obtain a reference noise level $\left(N_{\text {ref }}\right)$. Now, a design constraint can be added to the MDO formulation that will require a target noise reduction $(\Delta N<0)$ compared to the reference noise level. This design constraint can be written as $N_{\text {new }}-N_{\text {ref }} \leq \Delta N$, where $N_{\text {new }}$ is the noise level of the new configuration. The final step is to re-optimize the reference configuration with the same MDO formulation as before except with the added noise constraint. A new configuration will be obtained that has $\Delta N$ less noise. This procedure is shown in Figure 3.

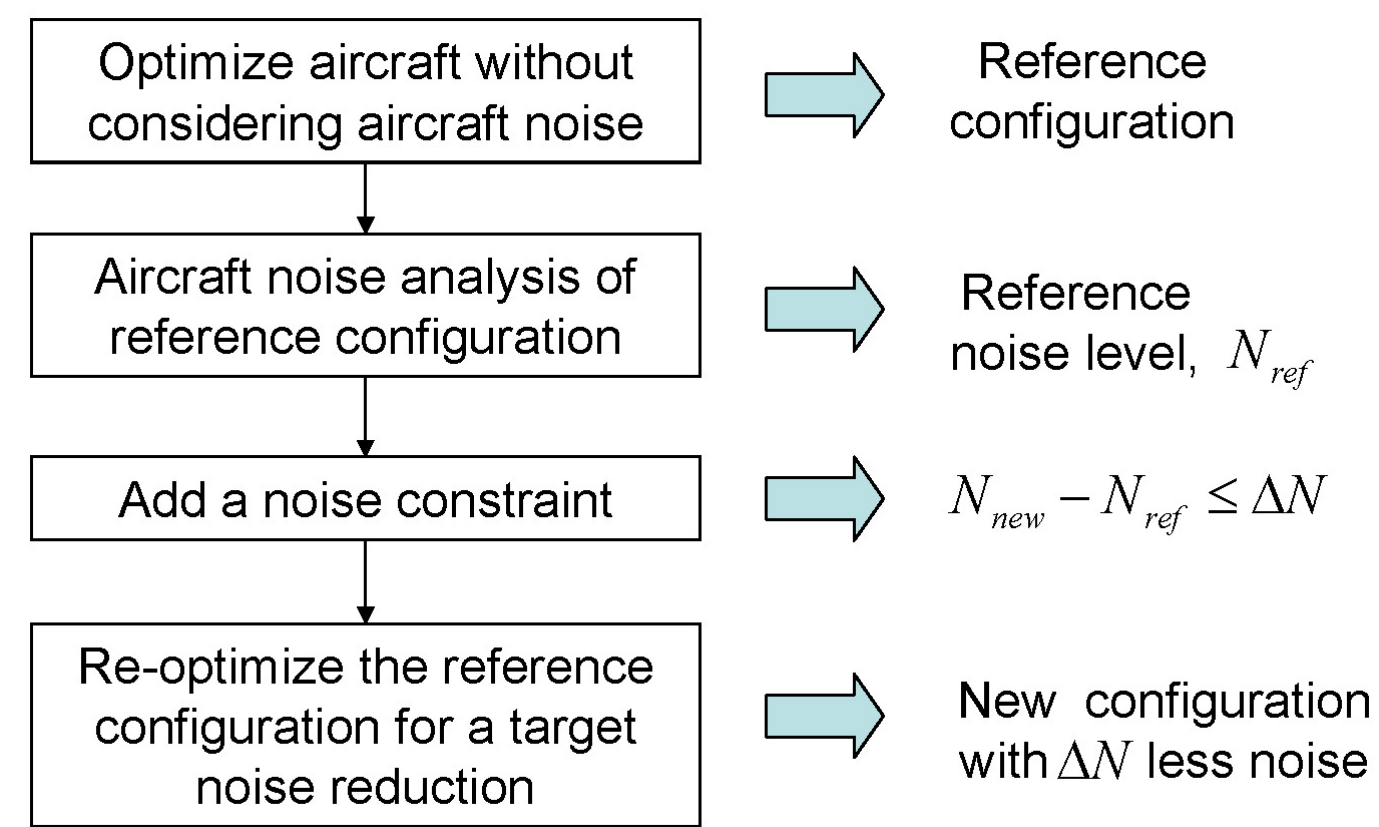

Figure 3. Incorporation of noise as a design constraint.

$\mathrm{ANOPP}^{11}$ is a semi-empirical code that uses publicly available noise prediction schemes and is continuously updated by NASA Langely. ANOPP uses "state of the art" noise prediction methods and is the industry standard. Therefore, ANOPP is used for airframe noise analysis.

Although the landing gear noise is currently the dominant airframe noise source, the landing gear noise model in ANOPP is not appropriate for use in design optimization, since it is a function of landing gear geometry, which is generally not included in a design optimization of the whole aircraft. Design of the landing gear is an entirely separate problem in itself, and much research is being conducted on landing gear noise reduction. ${ }^{23-26}$ However, the landing gear model in ANOPP can be used when performing an off-line noise analysis of the aircraft.

The three remaining airframe noise models in ANOPP (LE slat, the clean wing, and TE flap) are all related to the wing and tail surfaces of the aircraft. The noise of the high lift devices (LE slat and TE flap) are more dominant than the clean wing noise. The LE slat noise model in ANOPP assumes a fixed geometry of the slat ( $15 \%$ slat-chord to wing-chord ratio and full slat-span to wing-span). The TE flap noise model is proportional to the flap area $\left(S_{f}\right)$ and proportional to the sine squared of the flap deflection $\left(\delta_{f}\right)$. Furthermore, these three aerodynamic devices (the clean wing, LE slats, and TE flaps) are all interconnected. The wing design is based on the weight of the aircraft, the required performance, and the design constraints. The required size and function of the high-lift devices (LE slats and TE flaps) depend on the high-lift coefficient requirement at the approach condition and the size of the wing. Therefore, by reducing the highlift requirement at approach it is possible to reduce or eliminate noise due to the high-lift devices. Thus, by simplifying and/or reducing the size of the TE flaps, the high-lift capability (and noise) is reduced and the wing area needs to be increased and/or the angle of attack needs to be increased to meet the required high lift requirements set by the FAR, i.e., for transport aircraft $C_{L_{\max }} \geq 1.3^{2} C_{L_{a p p}}$. Clearly, MDO should be used to investigate this effect.

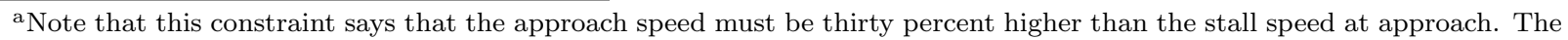
factor of 1.3 is an extreme case and could be lowered to $1.23 .^{27}$
} 


\section{MDO Framework}

The MDO framework, shown in Figure 4, integrates aircraft performance analysis codes and noise analysis codes using ModelCenter and Analysis Server software by Phoenix Integration ${ }^{\mathrm{b}}$.

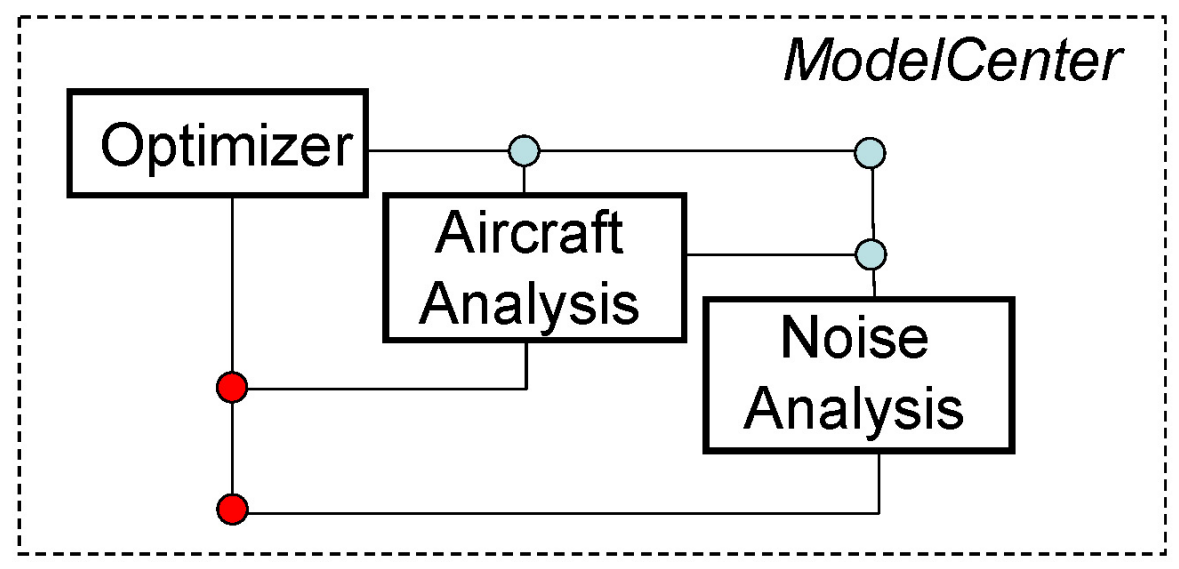

Figure 4. An N-squared diagram of the MDO framework.

An MDO program previously developed at Virginia Tech is employed for aircraft performance and weight analysis. The code is capable of analyzing both cantilever wing and Strut-Braced-Wing (SBW) transport aircraft using low- to medium fidelity analysis methods. The high-speed aerodynamics model is a combination of traditional aerodynamics estimation methods and response surface models, developed using Computational Fluid Dynamics (CFD) analysis, ${ }^{22,} 28$ accounting for parasite, induced, wave, interference drag, and trim drag. A low-speed aerodynamics model was added that employs semi-empirical methods for conventional transport aircraft provided by Torenbeek ${ }^{29}$ and Schemensky. ${ }^{30}$ Wing weight is calculated using a combination of NASA Langley's Flight Optimization Software (FLOPS ${ }^{31}$ and a piecewise-linear beam model, representing the wing structure as an idealized double-plate model, and in the case of SBW taking into account the influence of the strut on the structural wing design. ${ }^{32}$ Weights of the remaining components of the wing are calculated with FLOPS. A detailed description of the wing structures model can be found in. ${ }^{33}$ The weight of the individual components of the aircraft, such as the fuselage, tail surfaces, and payload, are calculated using FLOPS. Rubber engine sizing is used to scale the engine to meet thrust requirements. GE-90 class, high-bypass-ratio turbofan engines are assumed. Full details of the code are given in. ${ }^{32,34,35}$

The objective function selected is to minimize Take-Off Gross Weight (TOGW). A total of 17 design variables are used for cantilever wing aircraft (Table 1) and they include aircraft geometric properties (main wing, vertical tail, engine location, and high lift system) and operating parameters such as average cruise altitude, maximum sea level static thrust and fuel weight. The flap semi-span $\left(b_{f} / 2\right)$ and flap-chord to wing-chord ratio $\left(E_{f}\right)$ were chosen to be the high lift system design variables.

There are 16 design constraints which cover the aircraft geometry, takeoff, climb, cruise, and landing (Table 2). The same constraints are used for both cantilever wing and SBW, except for constraints number 10 and 11, which are only used for cantilever wing aircraft to ensure that there is enough room for the landing gear, which is assumed to be wing-mounted. The landing gear for SBW aircraft are assumed to be fuselage mounted.

Constraints number 13 to 16 pertain to the high lift system. Constraint 13 ensures that the tip of the trailing edge flap does not exceed $75 \%$ of the wing semi-span to allow room for the outboard ailerons. The maximum possible angle of attack is limited by the fuselage tail scrape angle $\left(\theta_{t s}\right)$ and the glide slope angle $\left(\gamma_{g s}\right)$ in constraint number 14. The tail scrape angle is set to 12 degrees and the glide slope angle is assumed to be -3 degrees, giving a maximum possible angle of attack of 15 degrees.

FAR Part 25 requires the maximum lift coefficient $C_{L_{\max }}$ at approach to be greater or equal to $(1.3)^{2} C_{L_{a p p}}$. Constraint 15 makes sure that this condition is fulfilled. Constraint 16 is included as a 'sanity-check' for the optimizer. This constraint limits the maximum lift coefficient attainable for the given type of high lift system. In this study, a conventional mechanical-type high lift system is used, and the maximum attainable

\footnotetext{
${ }^{\mathrm{b}}$ www.phoenix-int.com
} 
Table 1. Design variables for cantilever wing aircraft

\begin{tabular}{cclc}
\hline \hline Nr. & Design Variable & Description & Range \\
\hline 1 & $b / 2$ & Wing semi-span & $90.0-132.1$ \\
2 & $\eta_{b}$ & Wing break span station & $0.2-0.9$ \\
3 & $c_{r}$ & Wing root chord & $52-100 \mathrm{ft}$ \\
4 & $c_{b}$ & Wing break chord & $5-50 \mathrm{ft}$ \\
5 & $c_{t}$ & Wing tip chord & $5-50 \mathrm{ft}$ \\
6 & $(t / c)_{r}$ & Wing root thickness to chord ratio & $0.005-0.20$ \\
7 & $(t / c)_{b}$ & Wing break thickness to chord ratio & $0.005-0.20$ \\
8 & $(t / c)_{t}$ & Wing tip thickness to chord ratio & $0.005-0.20$ \\
9 & $\Lambda_{c / 4}$ & Wing quarter chord sweep & $0-40 \mathrm{deg}$. \\
10 & $t_{\text {skin }}$ & Wing skin thickness at centerline & $0.004-2.0 \mathrm{in}$. \\
11 & $k_{v t a i l}$ & Vertical tail scaling factor & $0.5-2$ \\
12 & $\eta_{\text {eng }}$ & Engine spanwise location & $0-1$ \\
13 & $b_{f} / 2$ & TE flap semi-span & $0-80 \mathrm{ft}$ \\
14 & $E_{f}$ & Flap-chord to wing-chord ratio & $0-0.35$ \\
15 & $W_{\text {fuel }}$ & Fuel weight & $100,000-400,000 \mathrm{lb}$ \\
16 & $T_{\text {max sls }}$ & Maximum sea level static thrust per engine & $10,000-150,000 \mathrm{lb}$ \\
17 & $h_{\text {cruise }}$ & Average cruise altitude & $10,000-50,000 \mathrm{ft}$ \\
\hline \hline
\end{tabular}

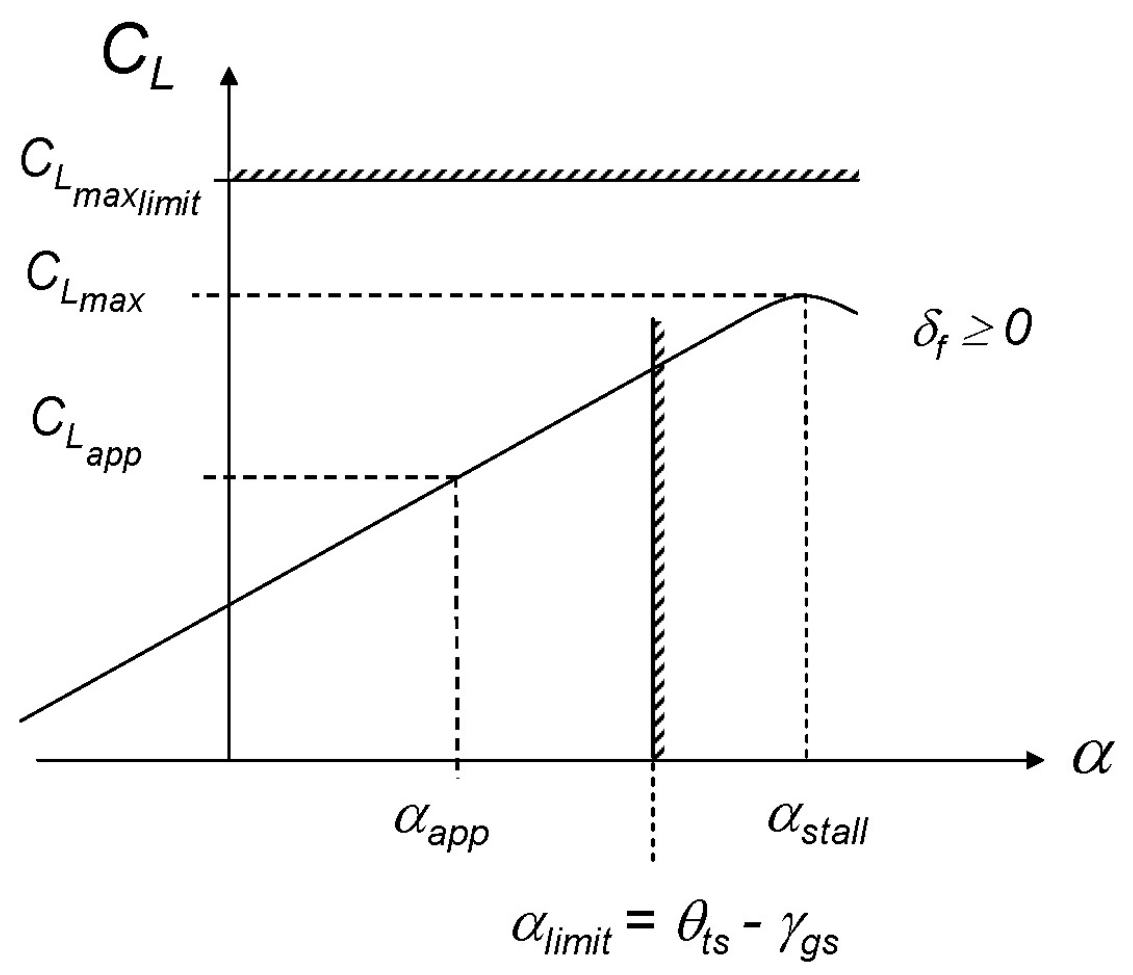

Figure 5. A typical wing lift curve with high-lift devices deployed.

lift coefficient at approach $\left(C_{L_{\max } \text { limit }}\right)$ is on the order of 3.0. Figure 5 graphically shows a typical wing lift curve along with the design constraints applied in this formulation.

The flap deflection angle $\left(\delta_{f}\right)$ required to fulfill the approach lift constraint (constraint 15 in Table 2) must be calculated given the flap semi-span and flap-chord to wing-chord ratio (which are set as design 
Table 2. Design constraints

\begin{tabular}{cll}
\hline \hline Nr. & Constraint & Description \\
\hline 1 & Range & $\geq 7,730 \mathrm{~nm}$ \\
2 & Fuel Capacity & Fuel Volume $\leq$ Fuel Tank Volume \\
3 & Balanced Field Length & $\leq 11,000 \mathrm{ft}$ \\
4 & Second Segment Climb Gradient & $\geq 0.027$ \\
5 & Missed Approach Climb Gradient & $\geq 0.024$ \\
6 & Rate of Climb at Top of Climb & $\geq 300 \mathrm{ft} / \mathrm{min}$ \\
7 & Landing Distance & $\leq 11,000 \mathrm{ft}$ \\
8 & Engine out & Required $C_{n} \leq$ Available $C_{n}$ \\
9 & Section $C_{l}$ & $\leq 0.8$ \\
10 & Wing break & $\geq 32 f t$ \\
11 & Engine spanwise location & $\geq 32 f t$ \\
12 & Wing tip deflection at taxi bump & $\leq 20 f t$ \\
13 & TE flap tip location & $\eta_{b_{o}} \leq 0.75$ \\
14 & Angle of attack at approach & $\leq \theta_{t s}-\gamma_{g s}$ \\
15 & Maximum lift coefficient at approach & $\geq 1.3^{2} C_{L_{a p p}}$ \\
16 & Maximum lift coefficient at approach & $\leq C_{L_{\text {max }} \text { limit }}$ \\
\hline \hline
\end{tabular}

variables). The flap deflection angle is found by performing a one-dimensional search between minimum $\left(\delta_{f_{l b}}\right)$ and maximum $\left(\delta_{f_{u b}}\right)$ allowable angles so that the approach lift constraint is fulfilled. Mathematically, this is formulated as $\min f\left(\delta_{f}\right)=\left|(1.3)^{2} C_{L_{a p p}}-C_{L_{\max }}\left(\delta_{f}\right)\right|$ for $\delta_{f} \in\left[\delta_{f_{l b}}, \delta_{f_{u b}}\right]$, where the lower and upper limits were set as $\delta_{f_{l b}}=0^{\circ}$ and $\delta_{f_{l b}}=30^{\circ}$.

\section{Results}

The study is in three parts. The first part optimizes a cantilever wing aircraft for different approach speeds. The second part introduces airframe noise into the MDO formulation, and cantilever wing aircraft are designed for minimum TE flap noise. The third and the last part compares cantilever wing and StrutBraced Wing (SBW) aircraft in terms of performance and airframe noise signature. A mission of 7,730 nm range with 305 passengers at cruise Mach 0.85 is assumed for all the studies. The approach speed for the second and third study is 140 knots.

\section{A. Effects of Approach Speed}

Figure 6 shows the variation in TOGW, reference area, and airframe noise for optimized configurations at approach speeds from 130 to 150 knots (a typical approach speed for a long range jet is $140 \pm 3$ knots $^{36}$ ). For all the configurations, the flap deflection hit the upper bound of 30 degrees and the angle of attack at approach was about 7.6 degrees. The results show that a large increase in wing reference area $(1,245 \mathrm{sqft}$ or $21.8 \%)$ is needed as the approach speed is reduced, leading to a significant weight penalty $(23,145 \mathrm{lb}$ or $3.8 \%)$. In spite of these planform changes, the reduction in airframe noise is only about 3 EPNdBs.

\section{B. TE Flap Noise Reduction}

The results in Figures 7 and 8 show that to reduce TE flap noise, the flap area is reduced by reducing the flap span, and at the same time the wing reference area and angle of attack both increase to meet the required lift at approach. The wing reference area increases by $760.6 \mathrm{sqft}(15.2 \%)$ and the angle of attack increases from 7.6 degrees to 12.8 degrees, while the TE flap is eliminated. The weight penalty is only about $1,878 \mathrm{lb}$ (an essentially constant TOGW) since the removal of flaps provide wing weight reduction and the wing span increased from $227.3 \mathrm{ft}$ to $233.6 \mathrm{ft}$, providing induced drag reduction to counter the aerodynamic performance penalty at the cruise condition due to a lowered wing aspect ratio (from 10.4 to 9.5). As a 
result, the TE flap can be removed together with all the noise associated with that device, without incurring any significant performance penalties. It should be noted that although noise due to the TE flaps has been eliminated, the overall airframe noise reduction is only $1 \mathrm{EPNdB}$. If noise due to the LE slats and landing gear is reduced, which is currently being pursued, the elimination of the flap will be very significant and the clean wing noise will be the next 'noise barrier'.

In this study a standard runway length of $11,000 \mathrm{ft}$ was used. The take-off and landing constraints were never active, meaning that the required take-off and landing lengths were less than 11,000 ft. It would be interesting to investigate a case with a $9,000 \mathrm{ft}$ runway. If the take-off and/or landing constraints would be active, then the wing area needed to meet them would have to increase, thereby incurring a weight penalty.
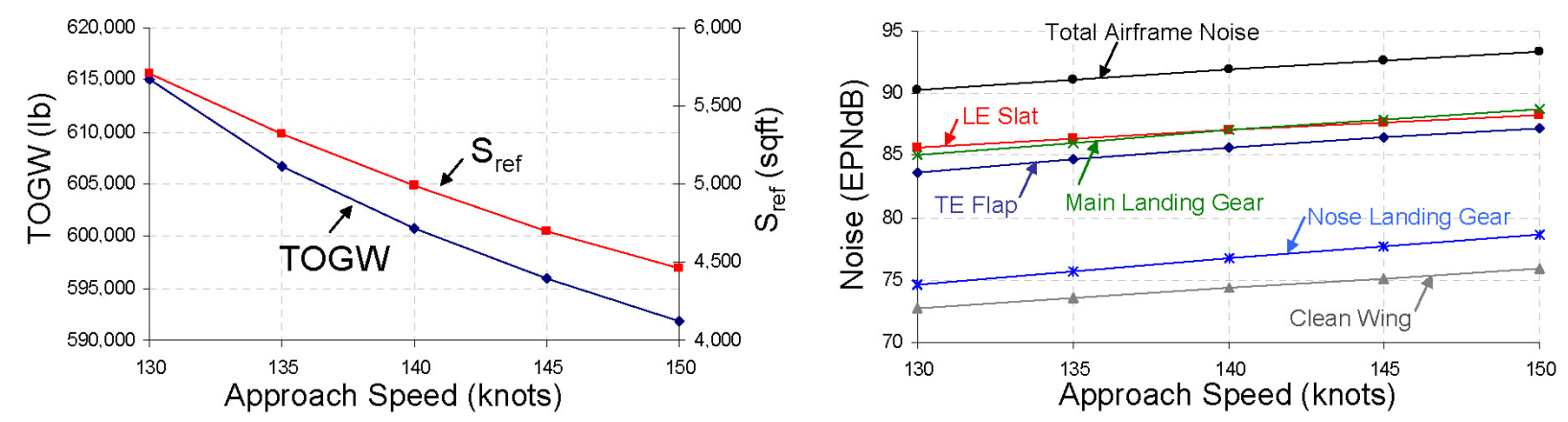

Figure 6. The change in aircraft take-off gross weight $(T O G W)$, wing reference area $\left(S_{r e f}\right)$, and airframe noise with approach speed.
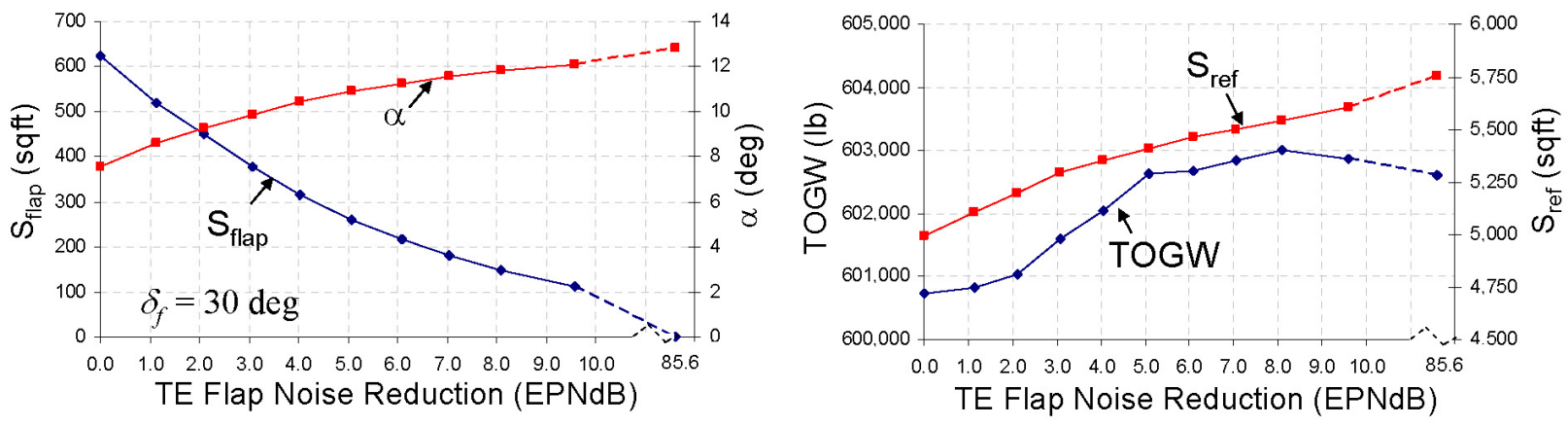

Figure 7. Change in aircraft properties with reduction in TE flap noise.
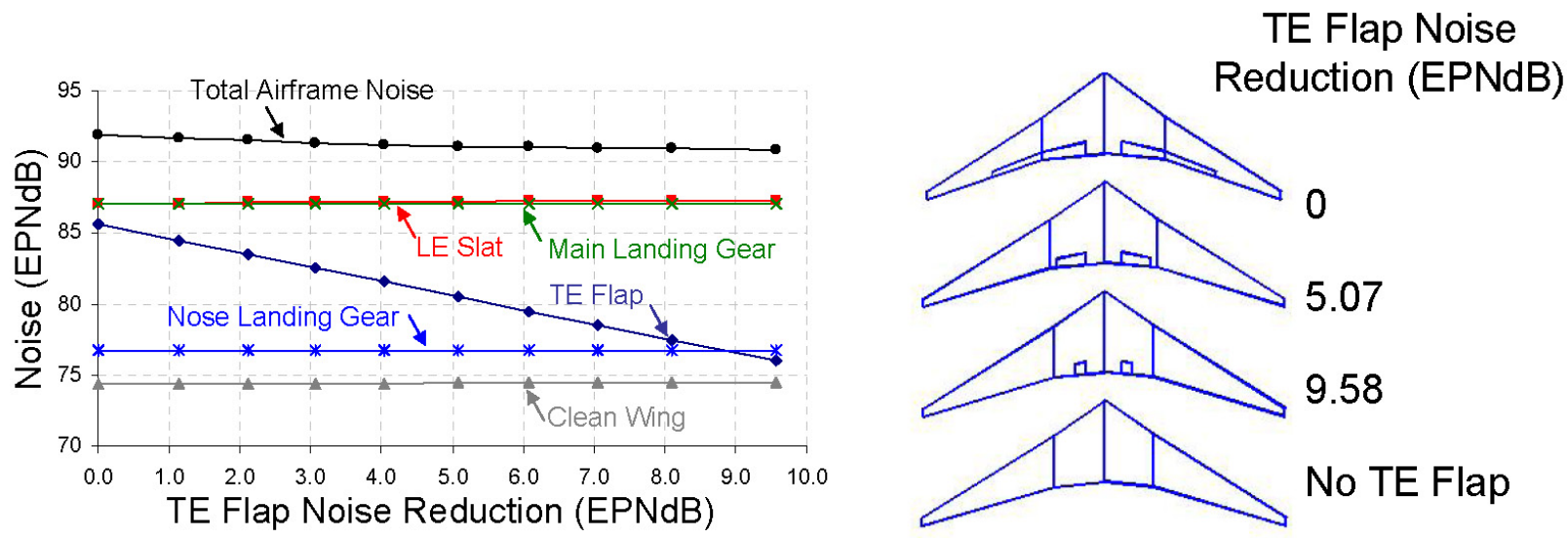

Figure 8. Change in airframe noise and TE flap geometry. 

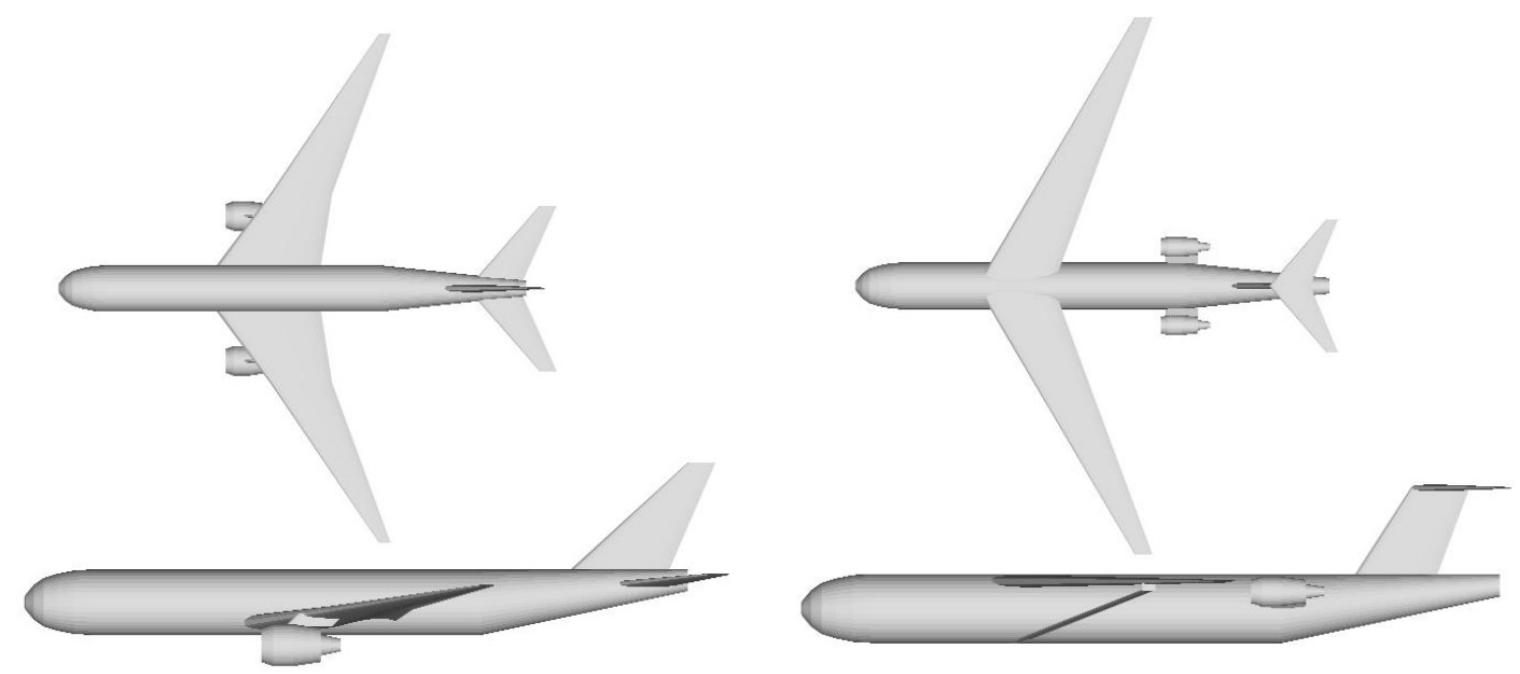

\begin{tabular}{|l|c|c|c|}
\hline Design Parameter & Cantilever Wing & SBW & Difference \\
\hline TOGW $(\mathrm{lb})$ & 601,901 & 543,066 & $-9.8 \%$ \\
Fuel Weight $(\mathrm{lb})$ & 230,614 & 196,236 & $-14.9 \%$ \\
Wing Weight $(\mathrm{lb})$ & 90,044 & 81,492 & $-9.5 \%$ \\
Aspect Ratio & 9.91 & 11.42 & $15.2 \%$ \\
L/D at Cruise & 21.14 & 23.54 & $11.4 \%$ \\
Specific Range (nm/1000 lb fuel) & 31.25 & 37.59 & $20.3 \%$ \\
\hline
\end{tabular}

Figure 9. Optimized cantilever wing and SBW aircraft.

\section{Cantilever Wing vs. SBW}

The results given in Figure 9 show that the addition of the strut allows for an increase in wing aspect ratio and a reduction in $t / c$. The reduction in $t / c$ allows the wing to unsweep. Thus, the wing weight is reduced by $9.5 \%$, while the aspect ratio is increased by $15.2 \%$. The resulting SBW design has $11.5 \%$ higher lift-to-drag ratio, requires $14.9 \%$ less fuel for the same mission, and has a $9.8 \%$ lighter $T O G W$. Both aircraft have a flap deflection of 30 degrees (which is the upper bound). The cantilever wing aircraft has an approach angle of attack of 7.7 degrees, whereas the SBW has a 5.8 degree angle of attack.

As can be seen from Table 3, the total airframe noise is found to be comparable for the cantilever wing and SBW aircraft. The main landing gear noise is $1.8 \mathrm{EPNdB}$ less for the SBW since there are only 4 wheels for each main gear, while the cantilever wing has 6 . The wing-strut noise was estimated as a clean wing TE noise and was found to be $67 \mathrm{EPNdB}$, which is significantly less than the dominating noise sources.

\section{Conclusions}

A methodology for designing low-airframe-noise transport aircraft has been developed and implemented in an MDO framework capable of optimizing both cantilever wing and SBW aircraft.

The results show that reducing airframe noise by reducing approach speed alone, will not provide significant noise reduction without a large performance and weight penalty. Therefore, more dramatic changes to the aircraft design are needed to achieve a significant airframe noise reduction, e.g., a re-design of the high-lift devices and the landing gear or even considering different aircraft configurations.

In another study we found that a cantilever wing aircraft can be designed to have minimal TE flaps without having a significant performance penalty. However, the take-off and landing constraints were not active since a standard runway length of $11,000 \mathrm{ft}$ was used. It would be interesting to repeat the study for a series of reduced runway lengths. The results suggest that aircraft should land at high angle of attack, or 
Table 3. Airframe noise analysis of optimized aircraft using ANOPP.

\begin{tabular}{lccc}
\hline \hline $\begin{array}{l}\text { Airframe } \\
\text { Component }\end{array}$ & $\begin{array}{c}\text { Cantilever } \\
(\mathrm{EPNdB})\end{array}$ & $\begin{array}{c}\text { SBW } \\
(\mathrm{EPNdB})\end{array}$ & $\begin{array}{c}\text { Difference } \\
(\mathrm{EPNdB})\end{array}$ \\
\hline Main Landing Gear & 87.02 & 85.21 & -1.81 \\
LE Slats & 87.06 & 87.02 & -0.04 \\
TE Flaps & 85.54 & 85.33 & -0.21 \\
Nose Landing Gear & 76.76 & 76.76 & 0.00 \\
Clean Wing & 74.31 & 74.41 & +0.10 \\
Wing-Strut & - & 67.16 & - \\
\hline \hline Total Airframe Noise & 91.89 & 91.27 & -0.62 \\
\hline \hline
\end{tabular}

around 12 - 13 degrees, to achieve a reduction in TE flap noise. This could prove to be a difficult challenge for the designer, since the high angle of attack will induce flow separation on the wing, and at high angles of attack the pilots vision of the runway will be limited. It is however not impossible to overcome these design challenges. Active flow control could be used to limit the flow separation, and the cockpit could be designed so the pilot could see the runway during approach and landing.

Without TE flaps, the landing gear and LE slats are the dominant airframe noise sources. To achieve any significant overall airframe noise reduction the noise due to those components needs to be reduced commensurately. A possible approach to minimize LE slat noise is to use LE droop-nose devices as those used on the A380. However, when that goal is achieved, the clean wing TE noise becomes the most dominant noise source. To reduce clean wing TE noise, a noise model more detailed than ANOPP should be used. The clean wing TE noise model proposed by Hosder et al. ${ }^{3}$ and the methodology presented in this study should be used in conjunction in the design optimization of an aircraft wing for minimum clean wing TE noise.

The last design study showed that a SBW aircraft with fuselage mounted engines can achieve a $10 \%$ reduction in TOGW and a $15 \%$ reduction in fuel weight compared to a cantilever wing aircraft for the same mission. Airframe noise analysis, using ANOPP, showed that a SBW aircraft, with a short fuselage-mounted landing gear, could have a similar or potentially a lower airframe noise level than a cantilever wing aircraft.

\section{Acknowledgements}

This research was in part supported by NASA Langley Research Center. Phoenix Integration Inc. provided the ModelCenter and Analysis Server software.

\section{References}

\footnotetext{
${ }^{1}$ Lilley, G.M. "The Prediction of Airframe Noise and Comparison with Experiment". Journal of Sound and Vibration, 239(4):849-859, 2001.

${ }^{2}$ Lockard, D.P., Khorrami, M.R., and Li, F. "High Resolution Calculation of a Simplified Landing Gear", 10th AIAA/CEAS Aeroacoustics Conference, AIAA Paper 2004-2887, May, 2004.

${ }^{3}$ Hosder, S., Schetz, J.A., Grossman, B., and Mason, W.H. "Airframe Noise Modeling Appropriate for Multidisciplinary Design and Optimization", AIAA Paper 2004-0698, AIAA Aerospace Sciences Meeting and Exhibit, Reno, NV, January, 2004.

${ }^{4}$ Anon. "Federal Aviation Regulations (FAR), Part 36. Noise Standards: Aircraft Type and Airworthiness Certification", U.S. Department of Transportation (DOT); Federal Aviation Administration (FAA), Washington D.C., 1969.

${ }^{5}$ Anon. "International Standards and Recommendation Practices-Environmental Protection - Annex 16 to the Convention on International Civil Aviation; Volume 1; Aircraft Noise. 2nd Edition", International Civil Aviation Organization (ICAO), Montreal, 1988.

${ }^{6}$ Antoine, N.E. and Kroo, I.A. "Aircraft Optimization for Minimal Environmental Impact", AIAA Paper 2002-5667, 9th AIAA/ISSMO Symposium on Multidisciplinary Analysis and Optimization, Atlanta, Georgia, 4-6 Sept. 2002.

${ }^{7}$ Anon. Aeronautics and Space Transportation Technology: Three Pillars for Success, Turning Goals Into Reality, NASA Annual Progress Report 1997-98.

${ }^{8}$ Lockard, D.P. and Lilley, G.M. "The Airframe Noise Reduction Challange", NASA Technical Memorandum 2004-213013, April, 2004.

${ }^{9}$ Caves, B.E., Jenkinson, L.R., and Rhodes, D.P. "Adapting Civil Aicraft Conceptual Design Methods to Account for Broader Based Constraints", AIAA Paper 97-5595, World Aviation Congress, Anaheim, CA, Oct. 13-16, 1997.
} 
${ }^{10}$ Caves, B.E., Jenkinson, L.R., and Rhodes, D.P. "Development of an Integrated Conceptual Aircraft Design and Aircraft Noise Model for Civil Transport Aircraft", ICAS Paper 98-6,4,3, 21st ICAS Congress, Melbourne, Australia, Sept. 13-18, 1998.

${ }^{11}$ Zorumski, W.E. "Aircraft Noise Prediction Program Theoretical Manual", NASA TM-83199, 1982.

${ }^{12}$ Antoine, N.E. and Kroo, I.A. "Optimizing Aircraft and Operations for Minimum Noise", AIAA Paper 2002-5868, AIAA's Aircraft Technology, Integration, and Operations (ATIO) Technical Forum, Los Angeles, California, 1-3 Oct. 2002.

${ }^{13}$ Antoine, N.E. "Aircraft Optimization for Minimal Environmental Impact". Ph.D. Dissertation, Stanford University, August 2004 .

${ }^{14}$ Antoine, N.E., Kroo, I.A., Willcox, K., and Barter, G. "A Framework for Aircraft Conceptual Design and Evironmental Performance Studies", AIAA Paper 2004-4314, 10th AIAA/ISSMO Symposium on Multidisciplinary Analysis and Optimization, Albany, New York, 30 Aug. - 1 Sept., 2004.

${ }^{15}$ Liebeck, R.H. "Design of the Blended Wing Body Subsonic Transport". Journal of Aircraft, 41(1):10-25, JanuaryFebruary 2004.

${ }^{16}$ Hill, G.A. and Olson, E.D. "Applications of Response Surface-Based Methods to Noise Analysis in the Conceptual Design of Revolutionary Aircraft", AIAA Paper 2004-4437, 10th AIAA/ISSMO Symposium on Multidisciplinary Analysis and Optimization, Albany, New York, 30 Aug. - 1 Sept., 2004.

${ }^{17}$ Hill, G.A., Brown, S.A., and Geiselhart, K.A. "Integration of Propulsion-Airframe-Aeroacoustic Technologies and Design Concepts for a Quiet Blended-Wing-Body Transport", AIAA Paper 2004-6403, AIAA's 4th Aircraft Technology, Integration, and Operations (ATIO) Technical Forum, Chicago, Illinois, 20 - 22 Sept., 2004.

${ }^{18}$ Burg, C.M., Hill, G.A., Brown, S.A., and Geiselhart, K.A. "Propulsion Airframe Aeroacoustics Technology Evaluation and Selection Using a Multi-Attribute Decision Making Process and Non-Deterministic Design", AIAA Paper 2004-4436, 10th AIAA/ISSMO Symposium on Multidisciplinary Analysis and Optimization, Albany, New York, 30 Aug. - 1 Sept., 2004.

${ }^{19}$ Manneville, A., Pilczer, D., and Spakovszky, Z.S. "Noise Reduction Assessments and Preliminary Design Implications for a Functionally-Silent Aircraft", 10th AIAA/CEAS Aeroacoustics Conference, AIAA Paper 2004-2925, 2004.

${ }^{20}$ Grasmeyer, J.M., Naghshineh, A., Tetrault, P.A., Grossman, B., Haftka, R.T., Kapania, R.K., Mason, W.H., and Schetz, J.A. "Multidisciplinary Design Optimization of a Strut-Braced Wing Aircraft with Tip-Mounted Engines". MAD Center Report MAD-98-01-01, January 1998.

${ }^{21}$ Gundlach, J.F., Tetrault, P-A., Gern, F.H., Naghshineh-Pour, A., Schetz, J.A., Ko, A., Mason, W.H., Kapania, R.K., Grossman, B., and Haftka, R.T. "Conceptual Design Studies of a Strut-Braced Wing Transonic Transport". Journal of Aircraft, 37(6):976-983, Nov.-Dec. 2000.

${ }^{22}$ Gern, F.H., Ko, A., Grossman, B., Haftka, R.T., Kapania, R.K., and Mason, W.H. "Transport Weight Reduction through MDO: the Strut-Braced-Wing Transonic Transport", 35th AIAA Fluid Dynamics Conference and Exhibit, Toronto, Canada, AIAA-2005-4667, June 6-9, 2005.

${ }^{23}$ Ravetta, P.A., Burdisso, R.A., and Ng, W.F. "Wind Tunnel Aeroacoustic Measurements of a 26\%-scale 777 Main Landing Gear Model", 10th AIAA/CEAS Aeroacoustics Conference, AIAA Paper 2004-2885, May, 2004.

${ }^{24}$ Piet, J.F., Davy, R., Elias, G., Siller, H.A., Chow, L.C., Seror, C., and Laporte, F. "Flight Test Investigation of Add-On Treatments to Reduce Aircraft Airframe Noise", 11th AIAA/CEAS Aeroacoustics Conference, AIAA Paper 2005-3007, May, 2005.

${ }^{25}$ Dobryzynski, W.M., Schöning, B., Chow, L.C., Wood, C., Smith, M., and Seror, C. "Design and Testing of Low Noise Landing Gears", 11th AIAA/CEAS Aeroacoustics Conference, AIAA Paper 2005-3008, May, 2005.

${ }^{26}$ Guo, Y.P., Yamamoto, K.J., and Stoke, R.W. "An Empirical Model for Landing Gear Noise Prediciton", 10th AIAA/CEAS Aeroacoustics Conference, AIAA Paper 2004-2888, May, 2004.

${ }^{27}$ van Dam, C.P. "The Aerodynamic Design of Multi-Element High-Lift Systems for Transport Airplanes". Progress in Aerospace Sciences, 38:101-144, 2002.

${ }^{28}$ Tetrault, P.A., Schetz, J.A., and Grossman, B. "Numerical Prediction of the Interference Drag of a Streamlined Strut Intersecting a Surface in Transonic Flow", AIAA Paper 2000-0509, 38th AIAA Aerospace Sciences Meeting and Exhibit, Reno, NV, January $10-13,2000$.

${ }^{29}$ Torenbeek, E. Synthesis of Subsonic Airplane Design, Delft University Press, Netherlands, 1982.

${ }^{30}$ Schemensky, R.T. "Development of an Empirically Based Computer Program to Predict the Aerodynamic Characteristics of Aircraft. Volume I: Empirical Methods", Air Force Flight Dynamics Laboratory AFFDL-TR-73-144, November 1973.

${ }^{31} \mathrm{McCullers,} \mathrm{L.A.} \mathrm{FLOPS} \mathrm{User's} \mathrm{Guide,} \mathrm{Release} 5.81$.

${ }^{32}$ Gern, F.H., Gundlach, J.F., Naghshineh-Pour, A., Sulaeman, E., Tetrault, P.A., Grossman, B., Kapania, R.K., Mason, W.H., Schetz, J.A., and Haftka, R.T. "Multidisciplinary Design Optimization of a Transonic Commercial Transport with a Strut-Braced Wing", World Aviation Conference and Exposition, SAE 1999-01-5621, San Francisco, CA, Oct., 1999.

${ }^{33}$ Naghshineh-Pour, A. "Structural Optimization and Design of a Strut-Braced Wing Aircraft". M.Sc. Thesis, Virginia Polytechnic Institute and State University, November 1998.

${ }^{34}$ Gundlach, J.F., Tetrault, P-A., Gern, F.H., Naghshineh-Pour, A., Schetz, J.A., Kapania, R.K., Mason, W.H., Grossman, B., and Haftka, R.T. "Multidisciplinary Design Optimization of a Strut-Braced Wing Transonic Transport", AIAA Paper 2000-0420, 38th Aerospace Sciences Meeting and Exhibit, Reno, Nevada, 10-13 January, 2000.

${ }^{35}$ Leifsson, L. "Multidisciplinary Design Optimization of Low-Noise Transport Aircraft". Ph.D. Dissertation, Virginia Polytechnic Institute and State University, August 2005.

${ }^{36}$ Rudolph, P.K.C. "High-Lift Systems on Commercial Subsonic Airliners", NASA Contractor Report 4746, September 1996. 